logue Staudinger et Rebel de 1901. Cependant, elle se trouve en Algérie aussi, car je vois dans mes notes que j'ai déterminé, en 1896, pour notre ancien collègue Al. OLivier, un exemplaire pris aux environs de Bône.

Les chenilles de Nyct. falsalis de Gafsa, élevées en mai, sur Asparagus albus L., ont donné leur papillon en octobre, novembre et décembre suivants. Celles de Bize, élevées en juin, sur Asparagus acutifolius L., ont donné leur papillon au commencement d'aoùt suivant. En France, comme en Mauritanie, l'espèce a donc au moins deux générations par an.

\title{
Description de nouvelles espèces de Lépidoptères Hétérocères de la Chine occidentale
}

par Charles ОвевтнÜв.

10 Chalcosinae. - Rhodopsona Jordani, n. sp. - Diffère de $R$. costata Walk. notamment par la couleur jaune de la bande courbe qui, partant de la base des supérieures, aboutit à l'angle interne. La tête et le collier sont jaunes.

Mou-pin. - Dédiée au $\mathrm{D}^{\mathrm{r}}$ Karl Jordan, de Tring.

Rhodopsona Reverdini, n. sp. - Diffère de $R$. costata parce que la tête étant rouge, le collier reste noir; la bande courbe est d'un rose carné légèrement orange.

Siao-lou. - Dédiée au Prol. J. Reverdin, de Genève.

Herpa elongatissima, n. sp. - Les ailes sont bien plus allongées que que chez $H$. sinica, basiflava et ochracea-luteola (ces deux dernières paraissant ètre les deux sexes d'une mème unité spécifique). Corps et ailes d'un même jaune pàle; antennes noires; les nervures finement indiquées en noir, aux ailes supérieures seulement. Les antennes de la \& sont épaisses, mais non pectinées. Celles du ơ sont fortement plumeuses.

Tse-kou.

Eterusia Culoti, n. sp. - Ailes allongées; fond des supérieures jaune clair et des inférieures jaune orangé. Les espaces intranervuraux sont ornés en dessus de longues taches d'un noir mat dont le centre est d'un bleu-verdâtre brillant; en dessous, le noir est presque entiè- 
rement envahi par la couleur bleue; le corps est noir en dessus, jaune en dessous. Le collier est bleu brillant. Les antennes du $\sigma^{7}$, seul sexe que je connaisse, sont noires, longues et pectinées. A Tse-kou, il y a une race locale plus petite, plus noire, que je distingue avec le nom de Dubernardi, n. var., en mémoire du missionnaire à qui j'en suis redevable.

Mou-pin, Tien-tsuen, Tay-tou-ho.

Eterusia moerens, n. sp. - Je connais seulement la ㅇ․ Espèce petite, noire sauf le centre des ailes inférieures qui est jaune.

Tse-kou.

Eterusia Lacreuzei, n. sp. - Assez grande espèce; ailes allongées; tête et corps d'un noir d'ardoise en dessus; épaulettes jaune clair; côtés et dessous de l'abdomen jaune clair; fond des ailes indigo en dessus; les supérieures avec des taches jaune clair, les inférieures avec des taches jaune orangé partant de la base et s'arrêtant un peu au delà du milieu des ailes. Aux supérieures, un gros point jaune clair isolé au bout de l'espace cellulaire; quelques rayonnements jaunes, très fins, vers le bord marginal. En dessous, les inférieures ont le bord costal et marginal d'un gris blanchâtre.

Tse-kou. - Dédiée à M. Lacreuze, lépidoptériste génevois.

Milionia Rehfousi, n. sp. - Grande espèce; fond des ailes blanchàtre avec toutes les nervures largement empâtées de gris noirâtre et plus ou moins finement recouvertes d'écailles bleu-brillant; le bord anal des inférieures est largement lavé de jaune; le collier est rouge; la tète, le corps, les premiers anneaux de l'abdomen sont d'un bleu brillant en dessus; en dessous, le corps et l'abdomen sont d'un jaune paille.

Siao-lou. - Dédiée à l'entomologiste de Genève M. Renfous.

2 Glonycinae, nova familia. - Glonycus Blachieri, n. sp. Superbe espèce paraissant extrême rare; plus grand que insolitus, du Sikkim, figurée par Butcer, sous le no 12 de la pl. LXXXIV de la part V de Lepid. Heter. in the Brit. Museum. En dessous, le corps et les ailes sont d'un rose carminé vif, parsemé de taches noires arrondies; les inférieures ont une grosse tache médiane hyaline, presque ronde; aux supérieures, l'extrémité apicale est plus claire et la nuance rose vif du fond y devient légèrement jaunâtre. En dessous, les teintes sont moins vives, les taches noires sont plus grosses; les pattes sont noires, sauf l'article médian de la $2^{\circ}$ paire qui est rose pàle.

Siao-lou. - Dédiée à M. le Prof. Charles Blachier, de Genève. 


\section{$2 \mathrm{BHL}$ Biodiversity Heritage Library}

1910. "Description de nouvelles especes de Lepidopteres heteroceres de la Chine occidentale." Bulletin de la Société entomologique de France 1910, 314-315.

View This Item Online: https://www.biodiversitylibrary.org/item/38239

Permalink: https://www.biodiversitylibrary.org/partpdf/151355

\section{Holding Institution}

Smithsonian Libraries

\section{Sponsored by}

Smithsonian

\section{Copyright \& Reuse}

Copyright Status: NOT_IN_COPYRIGHT

This document was created from content at the Biodiversity Heritage Library, the world's largest open access digital library for biodiversity literature and archives. Visit BHL at https://www.biodiversitylibrary.org. 